\title{
Trends in End-of-Life Care in Pediatric Hematology, Oncology, and Stem Cell Transplant Patients
}

\author{
Katharine E. Brock, MD, MS ${ }^{1}$, Angela Steineck, MD², and Clare J. Twist, MD ${ }^{1}$ \\ 1Division of Hematology/Oncology, Department of Pediatrics, Stanford University School of \\ Medicine, Stanford, California \\ ${ }^{2}$ Department of Pediatrics, Stanford University School of Medicine, Stanford, California
}

\begin{abstract}
Background-Decisions about end-of-life care may be influenced by cultural and diseasespecific features. We evaluated associations of demographic variables (race, ethnicity, language, religion, and diagnosis) with end-of-life characteristics (Phase I enrollment, do-not-resuscitate (DNR) orders, hospice utilization, location of death), and trends in palliative care services delivered to pediatric hematology, oncology, and stem cell transplant (SCT) patients.
\end{abstract}

Procedure-In this single-center retrospective cohort study, inclusion criteria were as follows: patients aged 0-35 who died between January 1, 2002 and March 1, 2014, and had been cared for in the pediatric hematology, oncology, and SCT divisions. The era of 2002-2014 was divided into quartiles to assess trends over time.

Results-Of the 445 included patients, $64 \%$ of patients had relapsed disease, $45 \%$ were enrolled in hospice, and $16 \%$ had received palliative care consultation. Patients with brain or solid tumors enrolled in hospice $(P<0.0001)$ and died at home more frequently than patients with leukemia/ lymphoma $(P<0.0001)$. Patients who received Phase I therapy or identified as Christian/Catholic religion enrolled in hospice more frequently $(P<0.0001$ and $P=0.03$, respectively). When patient deaths were analyzed over quartiles, the frequency of DNR orders $(P=0.02)$ and palliative care consultation $(P=0.04)$ increased over time. Hospice enrollment, location of death, and Phase I trial enrollment did not change significantly.

Conclusions-Despite increases in palliative care consultation and DNR orders over time, utilization remains suboptimal. No increase in hospice enrollment or shift in death location was observed. These data will help target future initiatives to achieve earlier discussions of goals of care and improved palliative care for all patients.

\section{Keywords}

end-of-life; hospice; palliative care; pediatric hematology/oncology; religion; Phase I trial

Correspondence to: Clare J. Twist, Division of Pediatric Hematology/Oncology, Department of Pediatrics, Stanford University School of Medicine, 1000 Welch Road, Suite 300, Palo Alto, CA 94304-1813, ctwist@ stanford.edu.

Conflicts of interest: Nothing to declare.

Additional Supporting Information may be found in the online version of this article. 


\section{INTRODUCTION}

Annually, there are approximately 12,400 new diagnoses of pediatric cancer in the United States, and cancer remains the leading disease-related cause of death in children.[1] Despite vast improvement in overall survival to approximately $80 \%$, one of five children diagnosed with cancer will die of their disease or treatment-related complications.[2] During the past decade, there has been a general trend to optimize supportive care throughout the entire disease trajectory, including concurrent palliative care services. The American Society of Clinical Oncology, the American Academy of Pediatrics, the Institute of Medicine, and the World Health Organization all advocate for a palliative approach when caring for patients with life-threatening, complex illness, ideally starting at diagnosis and continuing throughout the disease course.[3-8]

When providers focus on the palliative care needs of children with cancer, families report better preparedness for the end of life, improved quality of life, and decreased suffering.[911] Previous research explored the relationship of gender, race, ethnicity, religion and diagnosis with palliative care services and aggressiveness of care at the end of life for adult and pediatric cancer patients.[12-21] Research has shown that parents and clinicians prefer that a patient's end-of-life care and death occur at home. $[9,11,22,23]$ This was more likely to occur when a palliative care team was involved;[11] however, cultural and religious preferences may influence these decisions.[24] Although the literature describing preferences for end-of-life care in pediatric patients is growing, it remains limited to predominantly white, English-speaking patient populations with cancer diagnoses, providing little data on patients from other ethnic groups or those with hematologic and nonmalignant diseases.[9,12,16,19,25]

Our study aimed to explore the associations between demographic variables (race, ethnicity, language, religion, and diagnosis) and end-of-life characteristics (Phase I utilization, do-notresuscitate (DNR) order status, palliative care consultation, hospice enrollment, and location of death). Patients with hematologic malignancies less often utilize palliative care or hospice services at the end of life; $[15,26]$ we aimed to explore this in our ethnically diverse patient population. Our hypotheses were as follows: (i) race, ethnicity, language preference, and religion may influence end-of-life services received; (ii) solid and brain tumor patients would have a DNR or POLST (physician orders for life-sustaining treatment) order, enroll in hospice, and die at home more commonly when compared to patients with leukemia/ lymphoma or hematologic/immunologic diagnoses; (iii) patients who received palliative care consultation would be more likely to have a DNR/POLST, enroll in hospice, and to die at home. We sought to evaluate whether intensiveness of care (Phase I trial enrollment or having a stem cell transplant [SCT]) was correlated with more aggressive end-of-life care, hypothesizing that patients who received more intensive therapy would receive less palliative and hospice care, and die at home less often. Finally, we evaluated the trends over time in end-of-life care services delivered to patients cared for by pediatric hematology, oncology, and SCT divisions at a single tertiary care institution over a 13-year period, hypothesizing that there would be an observed increase in DNR/POLST orders, palliative care consultations, hospice enrollment, and death at home. 


\section{METHODS}

\section{Study Population}

Stanford University Institutional Review Board approval was waived for this retrospective analysis. A prospectively collected database of all patient deaths served to identify the cohort of pediatric hematology, oncology, and SCT patients from Lucile Packard Children's Hospital at Stanford who died between January 1, 2002 and March 1, 2014. Our institution serves children, adolescents, and young adults from Northern California, seeing approximately 170 new patients with cancer, 500 new patients with hematology diagnoses, and performing 30-40 SCTs annually.

Inclusion criteria were as follows: deceased patients with any diagnosis, between the age of 0-35 years at death, and cared for by the pediatric hematology, oncology, neurooncology, or SCT teams at any point during their disease course. Patients were included regardless of coexisting medical conditions, cause of death, or duration of care at Stanford.

\section{Data Collection}

Each patient's electronic health record (EHR) was reviewed to collect demographic information (medical record number, date of birth, date/age at diagnosis, date/age at death, gender, race/ethnicity, language, religion), disease information (diagnosis, relapse number, SCT status, cause of death, Phase I enrollment), and end-of-life characteristics (DNR/ POLST order status and date entered, autopsy status, palliative care consultation and date performed, hospice enrollment and date enrolled, location of death). Data were confirmed using an institutional EHR review tool, STRIDE.

Several strategies were used to ascertain missing data: querying the primary hematologistoncologist, social worker, or local hospice organization, internet searching, and reviewing handwritten records. Exact dates were recorded when available. If only a month/year format was found, the recorded date was defaulted to the first of the month. Diagnosis was collected as one of 11 categories (leukemia, lymphoma, bone sarcoma, soft tissue sarcoma, liver tumor, neuroblastoma, renal tumor, rare oncology, brain tumor, hematologic, and immunologic). These were collapsed to four categories for the purpose of analysis: (i) leukemia/lymphoma, (ii) solid tumors, (iii) brain tumors, and (iv) hematologic/immunologic diseases. Religious affiliation was collected as one of nine categories, and for the purpose of analysis was collapsed to three categories: (i) Christian/Catholic, (ii) other (including Buddhist, Hindu, Mormon, Muslim, Jewish, and Jehovah's Witness), and (iii) no preference/ none. The SCT cohort included both allogeneic and autologous transplant recipients. Death location was collected as five categories, and for analysis was collapsed to (i) home or inpatient hospice or (ii) hospital (our institution or any local hospital). For variables "days from DNR order to death" and "days in hospice," we assumed that the patient continued to have a DNR order or remained in hospice care until death, unless otherwise noted.

\section{Statistical Analysis}

To assess two-way associations between categorical demographic variables and end-of-life characteristics, Chi-square or Fisher's exact test (for sparse data) was used. As continuous 
data were nonnormally distributed, Wilcoxon rank-sum (Mann-Whitney U, for two independent groups) or Kruskal-Wallis test (nonparametric analysis of variance [ANOVA], for three or more independent groups) was used. Quartiles were a priori defined as follows: 2002-2004, 2005-2007, 2008-2010, and 2011-2014. To assess trends over quartiles, Cochrane-Armitage trend test was used for binary variables and nonparametric ANOVA for continuous variables. Crude and multivariate logistic regression models were used to evaluate the effect of confounding on the primary outcome of interest. All tests were twosided. $P$-values were reported without adjustment for multiple testing and were considered statistically significant if $P<0.05$. SAS statistical software, version 9.4, Enterprise Guide version 6.1 was used for all analyses (SAS Institute Inc., Cary, NC).

\section{RESULTS}

Four-hundred forty-five (445) patients who died between January 1, 2002 and March 1, 2014 were included for analysis. Patient demographics are shown in Table I. Thirty-three patients (7.4\%) were $\geq 18$ years (range 18-25) at diagnosis, and 86 patients (19\%) were $\geq 18$ years (range 18-33) at death. Although most patients spoke English, 20\% were Spanish speaking only, and nine other primary languages were reported. Most patients (69\%) identified as Christian/Catholic, but 12\% reported a different religious affiliation and 19\% reported no religious preference. The most common diagnoses were leukemia/lymphoma and brain tumors (Supplementary Table SI). Sixty-four percent of patients had at least one disease relapse and $29 \%$ had undergone SCT.

End-of-life characteristics of patients are shown in Table II. Nearly half of the patients had a DNR order or POLST in place (49\%), enrolled in hospice (45\%), and died in the hospital (49\%). Sixteen percent of patients received specialty palliative care consultation, occurring a median of 42 days prior to death. There was no difference in the frequency of palliative care consultation between patients who had relapsed disease or not (18\% vs. $15 \%$ respectively, $P$ $=0.47$ ).

\section{Associations of Demographic and End-of-Life Characteristics}

Race, ethnicity, language, and religion-based groups were defined and compared across all end-of-life characteristics. Race was not associated with palliative care consultation $(P=$ $0.22)$, DNR order status $(P=0.39)$, Phase I enrollment $(P=0.58)$, hospice enrollment $(P=$ $0.42)$, days from DNR to death $(P=0.65)$, or days in hospice $(P=0.26)$.

Similarly, ethnicity was also not associated with palliative care consultation $(P=0.49)$, Phase I enrollment $(P=0.07)$, hospice enrollment $(P=0.60)$, days from DNR to death $(P=$ $0.68)$, or days in hospice $(P=0.32)$. Hispanic/Latino patients had a DNR order more often than non-Hispanic/Latinos (66\% vs. $52 \%, P<0.01$, odds ratio [OR] 1.8, 95\% confidence interval [CI] 1.2-2.9). English and non-English speakers did not differ in regard to religion $(P=0.06)$, Phase I enrollment $(P=0.09)$, palliative care consultation $(P=0.07)$, location of death $(P=0.46)$, or hospice enrollment $(P=0.45)$.

In this series, the likelihood of death occurring at home was similar across race $(P=0.14)$ and ethnic groups $(P=0.59)$; among these deceased patients, $36 \%$ of Caucasian patients, 
$33 \%$ of Hispanic patients, $32 \%$ of Asian patients, and $15 \%$ of Black patients died at home. There was no statistically significant difference in end-of-life outcome variables between patients who identified as Christian from those who identified as Catholic; therefore, they were analyzed as one group. Patients identifying as Christian/Catholic had a DNR/POLST order more often than patients who identified as another religion (63\% vs. 36\%, $P<0.01)$, an association not confounded by ethnicity. Christian/Catholic patients utilized hospice $(55 \%)$ at a rate similar to those with no religious preference (57\%), but more commonly than patients with other religious beliefs $(33 \%)(P=0.03)$. The hypothesis that religion and ethnicity influence end-of-life services held true with regard to DNR orders but no relationship was observed between race and language with end-of-life characteristics.

\section{Associations of Disease Characteristics and End-of-Life Characteristics}

The association of diagnosis with end-of-life characteristics is shown in Table III. Patients with brain or solid tumors enrolled in Phase I trials $(P<0.01)$, hospice $(P<0.0001)$, and died at home $(P<0.0001)$ more frequently than patients with leukemia/lymphoma or hematologic/immunologic diagnoses, consistent with a priori hypotheses. Diagnosis was significantly associated with length of time from DNR order placement to death $(P<0.001)$, but not with palliative care consultation $(P=0.31)$, DNR order status $(P=0.27)$, or length of time in hospice $(P=0.11)$. Patients with hematologic/immunologic diagnoses represented $8.1 \%$ of the cohort, but accounted for $19.4 \%$ of infectious deaths and $23.5 \%$ of treatmentrelated deaths. No patients with hematologic/immunologic diagnoses enrolled in hospice; despite a median of 1.5 years from diagnosis to death and only $58 \%$ having undergone SCT, all died in the hospital.

\section{Treatment Intensity and Relation to End-of-Life Characteristics}

Contrary to our hypotheses, Phase I clinical trial participants more often enrolled in hospice ( $80 \%$ vs. $49 \%, P<0.0001$; OR $4.0,95 \%$ CI 1.9-8.3), an association that persisted after multivariate adjustment for age at death, religion, diagnosis, relapse number, and SCT status (Supplementary Table SII). Patients who received Phase I therapy died at home or an inpatient hospice facility more frequently (61\% vs. $38 \%, P<0.01$; OR $2.6,95 \%$ CI 1.6-5.0), although this association is confounded by diagnosis (Supplementary Table SIII).

In contrast, patients who had undergone SCT had a DNR order placed closer to death (median 4 vs. 10 days, $P=0.02$ ), enrolled in hospice less (32\% vs. 60\%, $P<0.0001$, OR $0.3,95 \%$ CI $0.2-0.5)$, and died at home less often ( $21 \%$ vs. $48 \%, P<0.0001$, OR $0.3,95 \%$ CI 0.2-0.5).

Also contrary to our hypotheses, patients who received specialty palliative care consultation ( $\mathrm{n}=69)$ were not more likely to have a DNR/POLST order in place $(66 \%$ vs. $55 \%, P=$ $0.09)$, utilize hospice $(P=0.66)$, spend more time in hospice $(P=0.95)$, or die at home $(P=$ 0.77). Patients who received palliative care consultation did have a DNR/POLST order for a longer time (median 15 vs. 7 days prior to death, $P=0.05$ ).

Although a DNR/POLST order was not an eligibility requirement for local hospice services, hospice enrollment was significantly associated with DNR status (64\% vs. $52 \%, P=0.02$, OR 1.6, 95\% CI 1.1-2.5), having a DNR/POLST order in place for a longer duration 
(median 20 vs. 3 days, $P<0.0001)$, and dying at home or inpatient hospice (75\% vs. $5 \%, P$ $<0.0001$, OR 60, 95\% CI 27-132).

There were no differences in cause of death $(P=1.0)$, location of death $(P=0.25)$, or frequency of DNR order $(0.41)$ for patients who died within 6 months of initial diagnosis compared to those died later. However, patients who died after 6 months from diagnosis were more likely to have relapsed disease $(P<0.0001)$, undergone SCT $(P<0.0001)$, received Phase I therapy $(P<0.001)$, and enrolled in hospice $(P=0.02)$.

\section{Trends in End-of-life Care Over Time}

An analysis of data over quartiles based on the date of death (2002-2004, 2005-2007, 20082010, and 2011-2014, where $\mathrm{n}=108,107,103$, and 127, respectively) revealed more patients having a DNR/POLST order in place $(64 \%, P=0.02)$ and a greater percentage of patients having received palliative care consultation in recent quartiles (27\%, $P=0.04$ ) (Fig. 1). However, hospice enrollment $(P=0.55)$, length of time spent in hospice $(P=0.94)$, and location of death $(P=0.07)$ have not changed over time. In the last two quartiles, $51 \%$ and $40 \%$ of patients who died did so at home or an inpatient hospice, respectively, compared with $27 \%$ and $42 \%$ in the first two quartiles. Median time from DNR order placement to death was 6-7 days from 2002-2010; from 2011-2014, median time from DNR order to death was 13 days $(P=0.07)$ (Supplementary Fig. 1).

\section{DISCUSSION}

We evaluated associations between demographic and end-of-life characteristics and investigated the trends over time in end-of-life care services delivered to 445 deceased pediatric hematology, oncology, and SCT patients at a single institution over a 13-year period. As we hypothesized, patients who died with malignant solid tumors or brain tumors were more likely to receive hospice care and to die at home, when compared to patients with leukemia/lymphoma or hematologic/immunologic diagnoses. Somewhat surprisingly, Christian/Catholic patients and Phase I clinical trial enrollees who died tended to have less aggressive end-of-life care. In recent years, palliative care consultation and DNR orders are utilized more frequently among patients who died.

In contrast to previous reports, $[15,18]$ we did not observe racial or ethnic differences in location of death. In our study population, Hispanic/Latino patients and Christian/Catholic patients were more likely to have a DNR/POLST in place, suggesting that cultural and religious beliefs may impact end-of-life care decision making. Although religiousness has been shown to be an important predictor of aggressive end-of-life care, $[13,14,21,27]$ there has been no consensus on the relationship between religious affiliation and end-of-life care in pediatrics.[16,17,28,29] When discussing care preferences, providers should acknowledge the role of spirituality, while recognizing the highly individual nature of these conversations.

Similar to prior studies, $[19,20,30,31]$ we observed that patients who died with brain and solid tumors more often enrolled in hospice and died at home compared to those with leukemia. As supportive care has improved,[32] patients with hematologic malignancies in this series were not more likely to die from early, unanticipated toxicities, which could 
impact the opportunity for palliative care. A disparity by diagnosis may be related to parent and provider perception about the likelihood of cure and therapy goals. Rosenberg et al. [33] found that parents and providers of patients with hematologic malignancies more often felt cure was likely compared to those with solid and brain tumors, and that this may account for observed differences in end-of-life preferences. It is possible that patients with hemato-logic/ immunologic diagnoses may also be more likely to perceive cure as likely and as the goal of therapy.

Contrary to our a priori hypothesis, we found that patients who had been enrolled on a Phase I trial were more likely to enroll in hospice prior to death. As early phase clinical trial involvement is typically associated with more aggressive end-of-life care, we hypothesize that more frequent physician visits while enrolled on a clinical trial may have increased the opportunity to discuss goals of care. This association should be interpreted with caution, as a larger study found no association between hospice utilization and Phase I trial enrollment in pediatric oncology patients.[28]

As goals of care conversation dates were not readily accessible, the date for DNR/POLST orders was used as a proxy. Physicians placed a DNR order approximately 2 weeks prior to death in the 2011-2014 quartile, compared to 1 week in earlier quartiles. The observed frequency and timing of DNR order placement is consistent with that reported from other institutions, ranging from $48 \%$ to $78 \%$.[19,28,30,34,35]

While about one-third of our patients died at home or at an inpatient hospice, half of the patients in this series died in the hospital; this has not changed over time. The location of death was missing for $15 \%$ of patients; this is likely to be non-random, thus the accurate percentage of patients dying at home is likely higher than reported. Compared to reports from other institutions, $[9,11,19,28,30,36]$ death outside the hospital was less common in this series (33\% vs. $35-70 \%$ ), which could be related to our large regional catchment area, limited rural hospice resources, socioeconomic factors, and cultural preferences. This apparent stability in the percentage of home deaths among children with cancer has been observed by others.[15] Nearly all patients who were never enrolled in hospice died in the hospital; yet, similar to the findings by Thienprayoon et al.,[19] 25\% of our hospice-enrolled patients ultimately died in the hospital. This could be due to family preference, but the potential gap between preferred and actual location of death may signal poor community support, insufficient local hospice resources, inadequate end-of-life care planning, or inability to deliver adequate supportive care and relief of suffering in the home.

It is surprising that no patients who died with hematologic/immunologic diagnoses enrolled in hospice or died at home. DNR orders were placed closer to death (median 2 days) when compared to those with cancer diagnoses. Despite great focus on concurrent palliative care for oncology patients, it is possible that palliative care interventions have neglected hematology and immunology patients. Patients with nonmalignant diseases can have a high symptom burden, and may ultimately undergo SCT. Our data suggest that these patients may benefit from focused intervention to more effectively address palliative care needs. 
The value of the role of the hematologist/oncologist in providing basic palliative care has been acknowledged,[7,37] but patient care disparities exist through this approach.[26,37] Specialty palliative care clinicians and psychosocial professionals can facilitate goals-of-care discussions and advance care planning,[38] provide an added layer of support for families, assist in care coordination, and relieve physical, emotional, and spiritual suffering.[7,39,40]

In this report, $16 \%$ of patients who died between 2002 and 2014 received specialty palliative care consultation. Expansion of the palliative care service's physician and pain management support at our institution occurred in 2008; as our palliative care services have grown, utilization of this service appears to be increasing over time, with nearly $30 \%$ of patients who died between 2011 and 2014 receiving palliative care consultation. Though improved compared to historical data,[41] this remains a lower rate of consultation than reported from other institutions [11,29] and may have impacted our ability to find an association with other end-of-life characteristics.

There are several limitations to this study. It is a single institution, retrospective study. During the 13-year interval, our institution utilized three different EHR systems, resulting in missing data variables for up to $15 \%$ of patients that could affect the final analysis. Race, ethnicity, and language are self-reported. In addition, at our institution, pediatric hematology and oncology patients are cared for by disease-specific teams, and thus, the observed end-oflife characteristics within a particular disease group may reflect the treatment and supportive care preferences of providers, rather than a characteristic of the underlying disease.

Importantly, the observed outcome measures are not necessarily reflective of patient and family preferences. Multiple religions were clustered for statistical analysis due to small numbers of participants in several religious groups (non-Catholic/Christian); these religions may not have similar end-of-life beliefs, warranting evaluation with a larger number of patients. Despite the limitations, this report adds to the demographic diversity of the current literature, as a larger percentage of our patients are Spanish speaking, Hispanic, or Asian compared to other reported studies. $[9,12,16,19,25]$

In previously reported studies, a majority of families noted home as the preferred location of death and a larger percentage of patients died at home. $[9,11,19,22,28]$ Given the constraints of this retrospective study, it is unclear if the location of death accurately reflects patient preferences or whether other medical, cultural, or socioeconomic factors were the driving forces in end-of-life choices. Seventy-five percent of patients who received hospice care ultimately died at home. This suggests that future efforts to standardize earlier advance care planning, document goals of care, strengthen hospice partnerships, and reduce barriers to effective palliative care may help in providing end-of-life care that is most consistent with the preferences of patients and families.

This study identifies the observed variations in end-of-life care received by patients with different underlying diagnoses, racial, ethnic, and religious backgrounds, and documents the increasing utilization of palliative care services and implementation of DNR/POLST orders over a 13-year span of time. These observations highlight the underutilization or gaps in care for certain groups of patients, and may help to target future initiatives to achieve earlier discussions of goals of care and concurrent palliative care. 


\section{Supplementary Material}

Refer to Web version on PubMed Central for supplementary material.

\section{ACKNOWLEDGMENT}

This work was conducted with the support from a KL2 Mentored Career Development Award of the Stanford Clinical and Translational Science Award to Spectrum (NIH KL2 TR 001083) awarded to K.E. Brock, PI.

\section{Abbreviations}

DNR do not resuscitate

EHR electronic health record

POLST physician orders for life-sustaining treatment

SCT stem cell transplant

\section{REFERENCES}

1. Ries, LAG.; Smith, MA.; Gurney, JG.; Linet, M.; Tamra, T.; Young, JL.; Bunin, GR. Cancer incidence and survival among children and adolescents: United States SEER Program 1975-1995. National Cancer Institute; 1999. SEER Program. NIH Pub. No. 99-4649

2. Howlader N, NA.; Krapcho, M.; Garshell, J.; Miller, D.; Altekruse, SF.; Kosary, CL.; Yu, M.; Ruhl, J.; Tatalovich, Z.; Mariotto, A.; Lewis, DR.; Chen, HS.; Feuer, EJ.; Cronin, KA. SEER cancer statistics review, 1975-2011. National Cancer Institute; Bethesda, MD:

3. Smith TJ, Temin S, Alesi ER, Abernethy AP, Balboni TA, Basch EM, Ferrell BR, Loscalzo M, Meier DE, Paice JA, Peppercorn JM, Somerfield M, Stovall E, Von Roenn JH. American society of clinical oncology provisional clinical opinion: The integration of palliative care into standard oncology care. J Clin Oncol. 2012; 30:880-887. [PubMed: 22312101]

4. American Academy of Pediatrics Section on Hospice and Palliative Medicine and Committee on Hospital Care. Pediatric palliative care and hospice care commitments, guidelines, and recommendations. Pediatrics. 2013; 132:966-972.

5. American Academy of Pediatrics Committee on Bioethics and Committee on Hospital Care. Palliative care for children. Pediatrics. 2000; 106:351-357. [PubMed: 10920167]

6. Institute of Medicine. When children die: Improving palliative and end-of-life care for children and their families-Summary. The National Academies Press; Washington, DC: 2003. p. 712

7. Institute of Medicine. Dying in America: Improving quality and honoring individual preferences near the end of life. The National Academies Press; Washington, DC: 2014. p. 638

8. National cancer control programmes: Policies and managerial guidelines. World Health Organization; Geneva: 2002.

9. Kassam A, Skiadaresis J, Alexander S, Wolfe J. Parent and clinician preferences for location of endof-life care: Home, hospital or freestanding hospice? Pediatr Blood Cancer. 2014; 61:859-864. [PubMed: 24265171]

10. Mack JW, Hilden JM, Watterson J, Moore C, Turner B, Grier HE, Weeks JC, Wolfe J. Parent and physician perspectives on quality of care at the end of life in children with cancer. J Clin Oncol. 2005; 23:9155-9161. [PubMed: 16172457]

11. Wolfe J, Hammel JF, Edwards KE, Duncan J, Comeau M, Breyer J, Aldridge SA, Grier HE, Berde C, Dussel V, Weeks JC. Easing of suffering in children with cancer at the end of life: Is care changing? J Clin Oncol. 2008; 26:1717-1723. [PubMed: 18375901]

12. Baker JN, Rai S, Liu W, Srivastava K, Kane JR, Zawistowski CA, Burghen EA, Gattuso JS, West $\mathrm{N}$, Althoff J, Funk A, Hinds PS. Race does not influence do-not-resuscitate status or the number or 
timing of end-of-life care discussions at a pediatric oncology referral center. J Palliat Med. 2009; 12:71-76. [PubMed: 19284266]

13. Balboni TA, Vanderwerker LC, Block SD, Paulk ME, Lathan CS, Peteet JR, Prigerson HG. Religiousness and spiritual support among advanced cancer patients and associations with end-oflife treatment preferences and quality of life. J Clin Oncol. 2007; 25:555-560. [PubMed: 17290065]

14. Balboni TA, Balboni M, Enzinger AC, Gallivan K, Paulk ME, Wright A, Steinhauser K, VanderWeele TJ, Prigerson HG. Provision of spiritual support to patients with advanced cancer by religious communities and associations with medical care at the end of life. JAMA Intern Med. 2013; 173:1109-1117. [PubMed: 23649656]

15. Cawkwell PB, Gardner SL, Weitzman M. Persistent racial and ethnic differences in location of death for children with cancer. Pediatr Blood Cancer. 2015; 62:1403-1408. [PubMed: 25787675]

16. Hileli I, Weyl Ben Arush M, Hakim F, Postovsky S. Association between religious and socioeconomic background of parents of children with solid tumors and DNR orders. Pediatr Blood Cancer. 2014; 61:265-268. [PubMed: 23940107]

17. Knapp C, Madden V, Wang H, Curtis C, Sloyer P, Shenkman E. Spirituality of parents of children in palliative care. J Palliat Med. 2011; 14:437-443. [PubMed: 21385082]

18. Loggers ET, Maciejewski PK, Paulk E, DeSanto-Madeya S, Nilsson M, Viswanath K, Wright AA, Balboni TA, Temel J, Stieglitz H, Block S, Prigerson HG. Racial differences in predictors of intensive end-of-life care in patients with advanced cancer. J Clin Oncol. 2009; 27:5559-5564. [PubMed: 19805675]

19. Thienprayoon R, Lee SC, Leonard D, Winick N. Racial and ethnic differences in hospice enrollment among children with cancer. Pediatr Blood Cancer. 2013; 60:1662-1666. [PubMed: 23733549]

20. Thienprayoon R, Lee S, Leonard D, Winick N. Hospice care for children with cancer: Where do these children die? J Pediatr Hematol Oncol. 2015; 37:373-377. [PubMed: 26090871]

21. Phelps AC, Maciejewski PK, Nilsson M, Balboni TA, Wright AA, Paulk ME, Trice E, Schrag D, Peteet JR, Block SD, Prigerson HG. Religious coping and use of intensive life-prolonging care near death in patients with advanced cancer. JAMA. 2009; 301:1140-1147. [PubMed: 19293414]

22. Bluebond-Langner M, Beecham E, Candy B, Langner R, Jones L. Preferred place of death for children and young people with life-limiting and life-threatening conditions: A systematic review of the literature and recommendations for future inquiry and policy. Palliat Med. 2013; 27:705713. [PubMed: 23612958]

23. Vickers J, Thompson A, Collins GS, Childs M, Hain R, Paediatric Oncology Nurses' Forum/ United Kingdom Children's Cancer Study Group Palliative Care Working Group. Place and provision of palliative care for children with progressive cancer: A study by the Paediatric Oncology Nurses' Forum/United Kingdom Children's Cancer Study Group Palliative Care Working Group. J Clin Oncol. 2007; 25:4472-4476. [PubMed: 17906208]

24. Wiener L, McConnell DG, Latella L, Ludi E. Cultural and religious considerations in pediatric palliative care. Palliat Support Care. 2013; 11:47-67. [PubMed: 22617619]

25. Feudtner C, Feinstein JA, Satchell M, Zhao H, Kang TI. Shifting place of death among children with complex chronic conditions in the United States, 1989-2003. JAMA. 2007; 297:2725-2732. [PubMed: 17595273]

26. Kassam A, Skiadaresis J, Alexander S, Wolfe J. Differences in end-of-life communication for children with advanced cancer who were referred to a palliative care team. Pediatr Blood Cancer. 2015; 62:1409-1413. [PubMed: 25882665]

27. Balboni T, Balboni M, Paulk ME, Phelps A, Wright A, Peteet J, Block S, Lathan C, Vanderweele T, Prigerson H. Support of cancer patients' spiritual needs and associations with medical care costs at the end of life. Cancer. 2011; 117:5383-5391. [PubMed: 21563177]

28. Levine DR, Johnson L-M, Mandrell BN, Yang J, West NK, Hinds PS, Baker JN. Does phase 1 trial enrollment preclude quality end-of-life care? Phase 1 trial enrollment and end-of-life care characteristics in children with cancer. Cancer. 2015; 121:1508-1512. doi: 10.1002/cncr.29230. [PubMed: 25557437] 
29. Johnston DL, Vadeboncoeur C. Palliative care consultation in pediatric oncology. Support Care Cancer. 2012; 20:799-803. [PubMed: 21479523]

30. Klopfenstein KJ, Hutchison C, Clark C, Young D, Ruymann FB. Variables influencing endof-life care in children and adolescents with cancer. J Pediatr Hematol Oncol. 2001; 23:481-486. [PubMed: 11878774]

31. Bradshaw G, Hinds PS, Lensing S, Gattuso JS, Razzouk BI. Cancer-related deaths in children and adolescents. J Palliat Med. 2005; 8:86-95. [PubMed: 15662177]

32. Wolfe J, Grier HE, Klar N, Levin SB, Ellenbogen JM, Salem-Schatz S, Emanuel EJ, Weeks JC. Symptoms and suffering at the end of life in children with cancer. N Engl J Med. 2000; 342:326333. [PubMed: 10655532]

33. Rosenberg AR, Orellana L, Kang TI, Geyer JR, Feudtner C, Dussel V, Wolfe J. Differences in parent-provider concordance regarding prognosis and goals of care among children with advanced cancer. J Clin Oncol. 2014; 32:3005-3011. [PubMed: 25024073]

34. Baker JN, Kane JR, Rai S, Howard SC, Hinds PS. Changes in medical care at a pediatric oncology referral center after placement of a do-not-resuscitate order. J Palliat Med. 2010; 13:1349-1352. [PubMed: 21034279]

35. Postovsky S, Levenzon A, Ofir R, Ben Arush MW. "Do not resuscitate" orders among children with solid tumors at the end of life. Pediatr Hematol Oncol. 2004; 21:661-668. [PubMed: 15626022]

36. Schmidt P, Otto M, Hechler T, Metzing S, Wolfe J, Zernikow B. Did increased availability of pediatric palliative care lead to improved palliative care outcomes in children with cancer? J Palliat Med. 2013; 16:1034-1039. [PubMed: 23901834]

37. Quill TE, Abernethy AP. Generalist plus specialist palliative care-Creating a more sustainable model. N Engl J Med. 2013; 368:1173-1175. [PubMed: 23465068]

38. Jacobs S, Perez J, Cheng YI, Sill A, Wang J, Lyon ME. Adolescent end of life preferences and congruence with their parents' preferences: Results of a survey of adolescents with cancer. Pediatr Blood Cancer. 2015; 62:710-714. [PubMed: 25545105]

39. Korones DN. Pediatric palliative care. Pediatr Rev. 2007; 28:e46-e56. [PubMed: 17670952]

40. Himelstein BP, Hilden JM, Boldt AM, Weissman D. Pediatric palliative care. N Engl J Med. 2004; 350:1752-1762. [PubMed: 15103002]

41. Johnston DL, Nagel K, Friedman DL, Meza JL, Hurwitz CA, Friebert S. Availability and use of palliative care and end-of-life services for pediatric oncology patients. J Clin Oncol. 2008; 26:4646-4650. [PubMed: 18824711] 


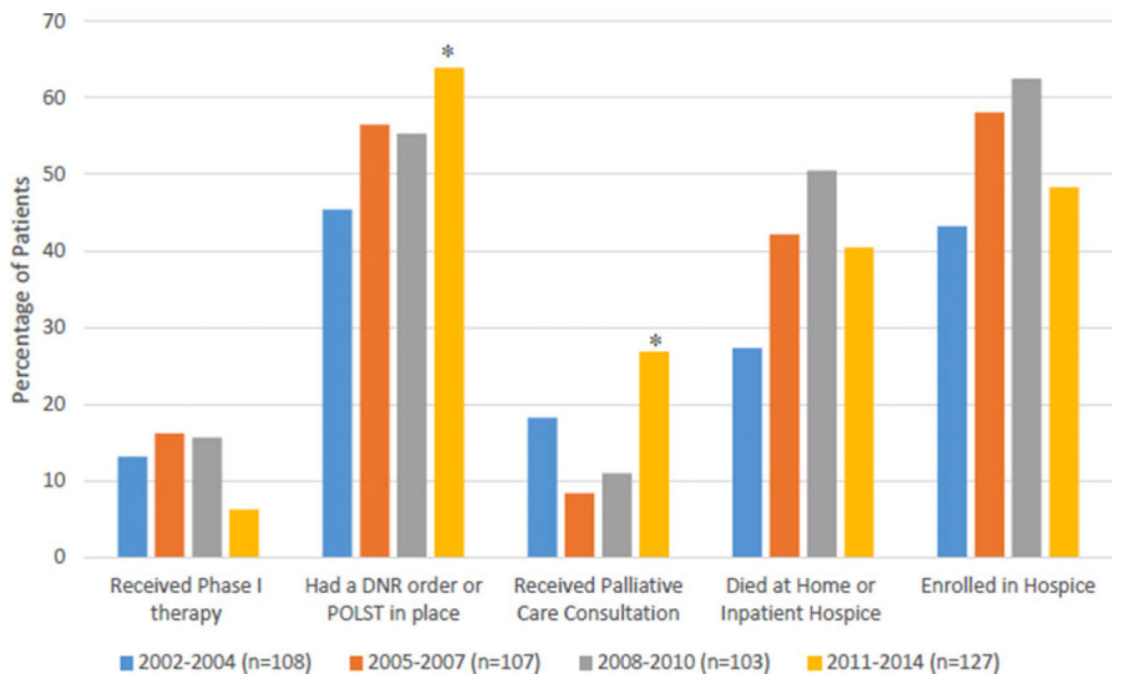

Fig. 1.

Trends over time in end-of-life care by quartile of death.

* Statistically significant $(P<0.05)$ for trend; had a DNR order or POLST in place $(P=0.02)$ and received palliative care consultation $(P=0.04)$. DNR, do not resuscitate; POLST, physician orders for life-sustaining treatment. 


\section{TABLE I}

\section{Demographics Characteristics of Patients}

\begin{tabular}{|c|c|c|}
\hline & $N(\%) N=445$ & Median (IQR) \\
\hline Age at diagnosis & & 8 (3-14 years) \\
\hline Age at death & & 11 (6-17 years) \\
\hline Years from diagnosis to death & & 1 ( $0.87-3$ years $)$ \\
\hline \multicolumn{3}{|l|}{ Gender } \\
\hline Female & $187(42.0 \%)$ & \\
\hline Male & $258(58.0 \%)$ & \\
\hline \multicolumn{3}{|l|}{ Race } \\
\hline White & $326(73.3 \%)$ & \\
\hline Asian & $77(17.3 \%)$ & \\
\hline Black & $17(3.8 \%)$ & \\
\hline Other $^{a}$ & $25(5.6 \%)$ & \\
\hline \multicolumn{3}{|l|}{ Ethnicity } \\
\hline Hispanic/Latino & $126(28.3 \%)$ & \\
\hline Non-Hispanic/Latino & $319(71.7 \%)$ & \\
\hline \multicolumn{3}{|l|}{ Language } \\
\hline English & $339(76.2 \%)$ & \\
\hline Spanish & $89(20.0 \%)$ & \\
\hline Other $^{b}$ & $17(3.8 \%)$ & \\
\hline \multicolumn{3}{|l|}{ Religion } \\
\hline Christian/Catholic & $286(69.1 \%)$ & \\
\hline Buddhist & $10(2.3 \%)$ & \\
\hline Hindu & $8(1.8 \%)$ & \\
\hline Muslim & $8(1.8 \%)$ & \\
\hline Mormon & $5(1.1 \%)$ & \\
\hline Jehovah's Witness & $3(0.6 \%)$ & \\
\hline Jewish & $3(0.6 \%)$ & \\
\hline Other religion & $12(2.7 \%)$ & \\
\hline None/no preference & $79(19.1 \%)$ & \\
\hline \multicolumn{3}{|l|}{ Diagnosis $^{c}$} \\
\hline Leukemia/lymphoma & $149(33.5 \%)$ & \\
\hline Brain tumor & $107(24.0 \%)$ & \\
\hline Solid tumor & $153(34.4 \%)$ & \\
\hline Hematologic & $29(6.5 \%)$ & \\
\hline Immunologic & $7(1.6 \%)$ & \\
\hline \multicolumn{3}{|l|}{ Number of Relapses } \\
\hline 0 & $156(35.6 \%)$ & \\
\hline 1 & $149(34.0 \%)$ & \\
\hline 2 or more & $133(30.3 \%)$ & \\
\hline
\end{tabular}




\begin{tabular}{lcc}
\hline & $\mathbf{N}(\boldsymbol{\%}) \mathbf{N}=\mathbf{4 4 5}$ & Median (IQR) \\
\hline Stem cell transplant performed & $128(28.8 \%)$ & \\
\hline
\end{tabular}

Numbers may not total $100 \%$ due to missing data - religion $(n=31)$ and number of relapses $(n=7)$.

${ }^{a}$ Other race includes Native American and Pacific Islander

$b$

$b$ other language includes Arabic, Sign Language, Chinese, Tagalog, Tangan, Hindi, Mandarin, and Korean

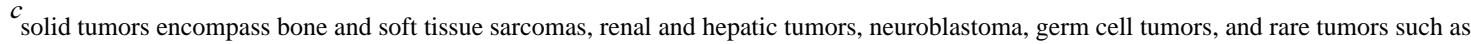
adrenocorticocarcinoma, retinoblastoma, nasopharyngeal carcinoma, desmoplastic small round blue cell tumor, and posttransplant lymphoproliferative disorder. Hematologic includes sickle cell, thalassemia, aplastic anemia, Langerhan's cell histiocytosis, and hemophagocytic lymphohistiocytosis. Immunologic includes, but is not limited to, severe combined immunodeficiency, common variable immunodeficiency, and chronic granulomatous disease. 


\section{TABLE II}

\section{End-of-Life Characteristics of Patients}

\begin{tabular}{|c|c|c|}
\hline & $N(\%) N=445$ & Median (IQR) \\
\hline \multicolumn{3}{|l|}{ Phase I trial participation } \\
\hline Enrolled & $55(12.4 \%)$ & \\
\hline Never enrolled & $385(86.5 \%)$ & \\
\hline Missing & $5(1.1 \%)$ & \\
\hline \multicolumn{3}{|l|}{ Location of death } \\
\hline Home & $135(30.3 \%)$ & \\
\hline Inpatient hospice & $14(3.1 \%)$ & \\
\hline Our hospital & $179(40.2 \%)$ & \\
\hline Local hospital & $40(9.0 \%)$ & \\
\hline Other & $11(2.5 \%)$ & \\
\hline Missing & $66(14.8 \%)$ & \\
\hline \multicolumn{3}{|l|}{ Autopsy status } \\
\hline Performed & $29(6.5 \%)$ & \\
\hline Not performed & $348(78.2 \%)$ & \\
\hline Missing & $68(15.3 \%)$ & \\
\hline \multicolumn{3}{|l|}{ DNR/POLST orders } \\
\hline DNR order or POLST in place & $219(49.2 \%)$ & \\
\hline No DNR or POLST in place & $172(38.7 \%)$ & \\
\hline Missing & $54(12.1 \%)$ & \\
\hline Days from DNR to death & & $9(2-29)$ \\
\hline \multicolumn{3}{|l|}{ Palliative care services } \\
\hline Patient received consultation & $69(15.5 \%)$ & \\
\hline No consultation & $341(76.6 \%)$ & \\
\hline Missing & $35(7.9 \%)$ & \\
\hline Days from the first relapse to consult & & $115(33-487)$ \\
\hline Days from consult to death & & $42(17-110)$ \\
\hline \multicolumn{3}{|l|}{ Hospice utilization } \\
\hline Enrolled in hospice & $201(45.2 \%)$ & \\
\hline No hospice utilization & $178(40.0 \%)$ & \\
\hline Missing & $66(14.8 \%)$ & \\
\hline Days in hospice care & & $28(14-67)$ \\
\hline
\end{tabular}

Days are presented as medians with interquartile range (IQR) as all variables were highly right skewed; DNR, do not resuscitate; POLST, physician order for life sustaining treatment. 
TABLE III

Associations of Diagnosis With End-Of-Life Characteristics

\begin{tabular}{|c|c|c|c|c|}
\hline \multirow[t]{3}{*}{ Diagnosis (n) } & $\begin{array}{l}\text { Enrolled in phase } \\
\text { I study }\end{array}$ & Enrolled in hospice & $\begin{array}{l}\text { Died at home or } \\
\text { inpatient hospice }\end{array}$ & $\begin{array}{c}\text { Days from DNR order to } \\
\text { death }\end{array}$ \\
\hline & $\mathbf{N}(\%)$ & $\mathbf{N}(\%)$ & $\mathbf{N}(\%)$ & Median (IQR) \\
\hline & $\mathbf{N}=\mathbf{5 5}$ & $N=201$ & $N=149$ & $\mathrm{~N}=\mathbf{2 1 5}$ \\
\hline Leukemia/lymphoma (149) & $12(8 \%)$ & $37(33 \%)$ & $30(25 \%)$ & $7.5(1-16)$ \\
\hline Solid tumor (153) & $26(17 \%)$ & $91(68 \%)$ & $69(53 \%)$ & $11.5(2-42)$ \\
\hline Brain tumor (107) & $17(16 \%)$ & $73(77 \%)$ & $50(61 \%)$ & $21(4.5-45.5)$ \\
\hline Hematologic/immunologic (36) & $0(0 \%)$ & $0(0 \%)$ & $0(0 \%)$ & $2(1-6)$ \\
\hline $\begin{array}{l}\text { Association of diagnosis with outcome ( } P \\
\text { value) }\end{array}$ & $<0.01$ & $<0.0001$ & $<0.0001$ & $<0.001$ \\
\hline
\end{tabular}

Percentage $=$ number with end-of-life characteristic/total $\mathrm{n}$ by diagnosis, excluding those with missing data. Of the total population (445), 440 had information on Phase I enrollment, 379 on hospice enrollment, and 379 on location of death. Of the 219 patients with a DNR order, 215 had information on the length of time the order was in place; DNR, do-not-resuscitate; IQR, interquartile range. 